DOSSIÊ ESPECIAL: DIDÁTICA SEM FRONTEIRAS

CHEREM, RAMMÉ, PEDRA \& OLMO (orgs.)

Revista X, vol.2, 2014

\title{
NO CAMINHO EM DIREÇÃO À INTERCOMPREEENSÃO. UMA REFLEXÃO EPISTEMOLOGICA ${ }^{1}$
}

\section{On The Way Towards Intercomprehension. An Epistemological Reflection}

\author{
Monica PALMERINI, Universidade de Roma Três \\ Serena FAONE, Universidade de Roma Três
}

Tradução de Karine Marielly ROCHA DA CUNHA, Universidade Federal do Paraná

\section{APRESENTAÇÃO}

O termo intercompreensão é relativamente novo no Brasil e representa uma área de estudos da linguística aplicada em forte expansão na Europa há mais de duas décadas. A primeira notícia da evocação do termo foi com o linguista francês Jules Ronjant em 1913. Posteriormente passou-se por anos de silêncio. No início da década de 90 Claire Blanche-Benveniste idealizou o manual EuRom4 com sua equipe. A mesma década foi marcada pela criação de outros métodos de ensino da Intercompreensão ou a da Didática do Plurilinguismo. No Brasil, a universidade pioneira na Intercompreensão foi a Federal do Rio Grande do Norte. Hoje em dia temos pesquisadores na UnB, UNICAMP, USP, UFPR e UNILA. O artigo que segue foi escrito por Monica Palmerini e Serena Faone, ambas pesquisadoras na Universidade de Roma 3 responsáveis pelo piloto de implantação do Manual EuRom5 coordenado pela professora Elisabetta Bonvino, sempre da Universidade de Roma 3, uma das autoras do Manual e expoente nos estudos da Intercompreensão.

Karine Marielly Rocha da Cunha

RESUMO: Neste artigo propomos uma reflexão sobre o conceito de Intercompreensão seguindo um percurso heurístico peculiar, provavelmente menos praticado, que vai da prática à teoria e não ao contrário. Nossas considerações estão baseadas na análise da aplicação em sala de aula do manual EurRom5. Essa experiência foi realizada durante o ano acadêmico italiano de 2008/2009 na Universidade de Roma 3 e teve como objetivo avaliar as dificuldades encontradas por italianos na compreensão de textos escritos em quatro línguas românicas: português, espanhol, catalão e francês.

1 Sul cammino verso l'intercomprensione. Una riflessione epistemológica. Disponível em: https://www.academia.edu/1203287/_con_Serena_Faone_.SSul_cammino_verso_lintercomprensione. Un a riflessione epistemologica e também na versão impressa REDINTER-Intercompreensão, 1, Chamusca, Edição Cosmos/REDINTER, 2010, pp.187-222. 


\section{DOSSIÊ ESPECIAL: DIDÁTICA SEM FRONTEIRAS \\ CHEREM, RAMMÉ, PEDRA \& OLMO (orgs.)}

Revista X, vol.2, 2014

PALAVRAS-CHAVE: Didática, EuRom5, Tipologia, Distância Percebida, Direção

ABSTRACT: In this paper we propose a reflection on the concept of Intercomprehension following a peculiar euristic procedure, probably less practised, which moves from the practice to the theory, and not vice-versa. Namely, our considerations are based on the classroom experimentation of the materials for the new manual of EuRom5, to be published shortly. This experience took place during the academic year of 2008/2009 at the University of Roma and it was intended to evaluate the difficulties met by Italian speakers who were confronted with the task of comprehending texts written in four romance languages: Portuguese, Spanish, Catalan and French.

KEYWORDS: language teaching, EuRom5, typology, perceived distance, direction

\section{INTERCOMPREENSÃO²: DE UMA EXPERIÊNCIA DIDÁTICA A UMA REFLEXÃO EPISTEMOLÓGICA}

\section{A IC como fenômeno comunicativo}

A epistemologia (do grego epistéme = "ciência" e logos = "discurso") ou, mais comumente, filosofia da ciência, é a disciplina que estuda criticamente a estrutura formal do conhecimento científico, isto é, a reflexão filosófica sobre a linguagem, os métodos, as organizações internas e os resultados das várias ciências para definir a natureza e o valor do saber científico.

O presente artigo é uma tentativa de sondar, na perspectiva epistemológica, o campo de pesquisa científica ligado em modo mais ou menos estável ao termo intercompreensão. Uma primeira definição "operativa" do nosso objeto de pesquisa coloca-se sob o plano empírico da observação da prática comunicativa. Antes de um conceito, a intercompreensão é:

\footnotetext{
"aquele fenômeno (grifo nosso) que acontece quando duas pessoas se comunicam entre elas falando cada uma a sua própria língua e compreendendo a língua do outro. Tal definição é baseada na ideia de que os falantes sejam capazes de compreender em grande escala um texto escrito ou oral de uma língua próxima, mesmo não tendo nunca seguido um percurso sistemático de estudo de tal língua.” (Bonvino, 2009:229)
}

Esta prática de intercomutabilidade ou mutua compreensão, muito comum em uma variedade de contextos históricos culturais (basta pensarmos à história dos países escandinavos ou mesmo às comunidades eclesiásticas na Europa central e meridional no

\footnotetext{
${ }^{2}$ Doravante, nos títulos, será usada a sigla IC.
} 


\section{DOSSIÊ ESPECIAL: DIDÁTICA SEM FRONTEIRAS \\ CHEREM, RAMMÉ, PEDRA \& OLMO (orgs.)}

Revista X, vol.2, 2014

período medieval tardio) ${ }^{3}$ adquire o status de objeto de pesquisa científica no âmbito dos estudos de linguística de contato, para depois, suscitar um notável interesse e conhecer uma ampla difusão a partir do fim dos anos 90, no campo da didática das línguas, onde se transforma em um elemento de grande importância para vários tipos de pesquisas.

\section{Centralidade da prospectiva didática}

Uma questão que se apresenta muito frequentemente é a de decidir qual o tipo de pesquisa adotar quando se tem um problema experimental (empírico). Esta escolha é importante já que condicionará aquilo que aceitaremos como verdade ou não. Todavia, acreditamos que o ponto de vista da epistemologia ${ }^{4}$ não concerne tanto o fato de demonstrar a legitimidade de um certo tipo de pesquisa como o único capaz de conduzir à verdade, quanto a possibilidade de justificar a preferência por um tipo de procedimento de pesquisa em detrimento a outro.

Em relação a isso, ao apresentar as nossas considerações epistemológicas sobre a intercompreensão, consideramos necessário explicitar o ponto de vista que caracterizará a nossa abordagem. A esse propósito, a evolução dos estudos no âmbito em questão apresenta um quadro o qual ponto principal é a nítida predominância de uma específica prospectiva sobre esse fenômeno comunicativo, e isto é, a didática inerente ao ensino das línguas estrangeiras. Este é, segundo o nosso ponto de vista, o domínio de aplicação da intercompreensão.

A cultura ocidental, e em particular a sociedade europeia moderna, começou, de fato, a manifestar uma aguda sensibilidade em relação à questão, estratégica, da comunicação entre os falantes das numerosas línguas que compõem o mosaico europeu. Assim traz um documento da Délégation Génerale à la Langue Français et aux Langues de France:

\footnotetext{
${ }^{3}$ Blanche-Benveniste (1997); Schmit Jensen (1997), partes de um número especial da revista Le Français dans le monde.

${ }^{4}$ Este ramo da filosofia conheceu um notável desenvolvimento no século passado, depois da crise do mecanismo positivista determinada pelas descobertas.
} 


\title{
DOSSIÊ ESPECIAL: DIDÁTICA SEM FRONTEIRAS \\ CHEREM, RAMMÉ, PEDRA \& OLMO (orgs.)
}

Revista X, vol.2, 2014

\begin{abstract}
«L'Union européenne est plurilingue, dans sa réalité quotidienne comme dans sa législation. Le recours à une seule langue de communication etre les différentes peuples européens ferait peser un risque énorme sur la capacité de l'Europe à faire vivre ensemble des cultures et des langues diverses $[\ldots]^{5}$. » (DGLFLF 2007 :3)
\end{abstract}

A questão fundamental parece aquela de valorizar e fazer dialogar a componente de unidade e afinidade e a componente de diversidade que convivem no espaço sociocultural, linguístico e político europeu. Está inserida neste contexto a referência a uma habilidade de mútua compreensão ou intercompreensão, que constitui um elemento de impulso a favor do desenvolvimento da integração e do sentido de fazer parte, possuir elementos comuns e, propõe-se como objeto de comunicação e de reflexão, defende a dignidade das realidades linguísticas consideradas minoritárias no quadro das línguas oficiais da Europa. Com o objetivo de alcançar o desenvolvimento de uma difusa consciência cultural plurilíngue vem, então, fortemente percebido a função fundamental da educação linguística, isto é, o modo no qual vem estabelecida a didática das línguas estrangeiras no espaço europeu.

Como resposta ao interesse suscitado pela intercompreensão, temos, há mais ou menos 20 anos assistido à apaixonada elaboração, por parte de muitos pesquisadores europeus, de programas científicos destinados ao desenvolvimento de uma nova metodologia de didática das línguas estrangeiras inspirada nos princípios da intercompreensão. É nesse contexto que se enquadram muitos projetos, de âmbito nacional e internacional como, por exemplo, no que concerne às línguas românicas, EuRom4, EuroComRom, Galatea, Galanet, Itinerários Românicos, Euromania, EuRom5 $5^{6}$.

É a partir da observação desta especificidade da intercompreensão como fenômeno comunicativo do qual a realidade sociocultural europeia "viu" a potencialidade aplicativa do instrumento de educação linguística plurilíngue, que toma forma a abordagem que caracteriza o nosso trabalho: o objetivo do presente artigo é aquele de propor uma reflexão sobre o conceito e sobre a definição de intercompreensão seguindo um percurso heurístico peculiar, provavelmente pouco comum, que se move do domínio da aplicação prática em direção à reflexão teórica e não ao contrário. Em

\footnotetext{
5 “A União Europeia é plurilíngue, na sua realidade cotidiana como na sua legislação. O recurso a uma só língua de comunicação entre os diferentes povos europeus faria pensar em um enorme risco quanto à capacidade da Europa de fazer conviver culturas e línguas diferentes [...]."

6 Para o detalhamento dos projetos europeus no âmbito das línguas românicas, consultar Tost Planet (2005:15-54).
} 


\section{DOSSIÊ ESPECIAL: DIDÁTICA SEM FRONTEIRAS \\ CHEREM, RAMMÉ, PEDRA \& OLMO (orgs.)}

Revista X, vol.2, 2014

outras palavras, o objetivo proposto é de usar uma experiência concreta de aplicação da intercompreensão no campo do ensino das línguas estrangeiras como base para florescer considerações de ordem epistemológica sobre esse setor de conhecimento científico.

O ponto de partida das nossas reflexões é a análise da experiência em aula com o material do projeto EuRom5, aplicado no ano acadêmico italiano 2008/2009 na Universidade de Roma 3 e coordenado por Elisabetta Bonvino. O experimento propunha avaliar in loco as dificuldades reais encontradas por italianos na compreensão de textos escritos em outras línguas românicas: português, espanhol, catalão e francês ${ }^{7}$.

O resultado desse experimento nos permitirá, na terceira parte do presente artigo, tecer considerações a respeito de diversos pontos de interesse epistemológico, que podemos resumir no modo seguinte, utilizando a definição de epistemologia dada na abertura do parágrafo 1.1:

a) Linguagem: o termo e o conceito de intercompreensão;

b) Método: a intercompreensão como objeto de pesquisa linguística;

c) Organização Interna: didática tradicional e didática plurilíngue;

d) Resultados: a intercompreensão como habilidade;

\section{Verso EuRom5: um experimento de didática da IC entre as línguas românicas}

Um dos primeiros programas a apresentar-se como intérprete, na Europa, da ideia de intercompreensão entre as línguas românicas no campo da didática foi EuRom. O projeto nasceu em 1989 como programa universitário de pesquisa no âmbito da análise contrastiva das línguas românicas. Idealizado por Claire Blanche Benveniste e patrocinado pelo programa Socrates LINGUA da Comissão Europeia, foi conduzido por uma equipe de pesquisadores de quatro universidades europeias: André Valli de Aix-enProvence, Antonia Mota de Lisboa, Izabel Uzganga de Vivar de Salamanca e, por fim, Raffaele Simone e Elisabetta Bonvino da Universidade de Roma 3. A experiência de anos de pesquisa e aplicações no âmbito deste projeto levou à publicação de um manual intitulado EuRom4: método de ensino simultâneo de quatro línguas românicas, publicado pela La Nuova Italia em 1997. O manual é direcionado a falantes de uma das

\footnotetext{
${ }^{7}$ No EuRom5 as línguas consideradas serão sempre mencionadas na seguinte ordem e com as seguintes siglas: português (PT), espanhol (ES), catalão (CA) e francês (FR). Essa escolha é justificada pela vontade de refletir os limites linguísticos entre as línguas românicas, de acordo com a proximidade geográfica das mesmas.
} 


\title{
DOSSIÊ ESPECIAL: DIDÁTICA SEM FRONTEIRAS \\ CHEREM, RAMMÉ, PEDRA \& OLMO (orgs.)
}

Revista X, vol.2, 2014

línguas pertencentes à família das línguas românicas (português, espanhol, espanhol, francês e italiano), adultos, com um bom nível de escolarização, bons leitores em língua materna. A hipótese de fundo que inspirava o projeto era que a aquisição de uma competência receptiva (passiva) plurilíngue é facilitada para aqueles que já falam uma língua da mesma família. O programa se configurava portanto como uma abordagem simultânea e coletiva, guiada por um mediador, objetivando a aquisição em um tempo brevíssimo (mais ou menos 40 horas) da competência de compreensão escrita nas quatro línguas em questão mediante o uso do material impresso (um guia gramatical) e sonoro (gravações autênticas). A intercompreensão configura-se portanto como uma competência parcial e aproximativa:

\begin{abstract}
"C'est aussi dans cette perspective que la notion de compétence partielle dans une langue donnée peut avoir un sens : il ne s'agit pas de se satisfaire, par principe ou par réalisme, de la mise en place d'une maîtrise limitée ou sectorisée d'une langue étrangère par un apprenant, mais bien de poser que cette maîtrise, imparfaite à un moment donné, fait partie d'une compétence plurilingue qu'elle enrichit. Il s'agit aussi de préciser que cette compétence dite «partielle», inscrite dans une compétence plurielle, est en même temps une compétence fonctionnelle par rapport à un objectif délimité que l'on se donne. La compétence partielle dans une langue donnée peut concerner des activités langagières de réception (mettre l'accent par exemple sur le développement d'une capacité de compréhension orale ou écrite); elle peut concerner un domaine particulier et des tâches spécifiques (permettre par exemple à un employé de la poste de donner des renseignements à des clients étrangers d'une langue donnée sur les opérations postales les plus courantes)." (CECRL ${ }^{8}$ 2001: 105)
\end{abstract}

O objetivo final do percurso é alcançar uma competência receptiva colocável no nível B do Quadro Comum Europeu de Referência para as Línguas (QCERL). Em seguida, mostramos a ilustração da tipologia do alvo desejado no nível já indicado e a descrição do perfil de competência que deve caracterizá-lo (CECRL 2001:25-27):

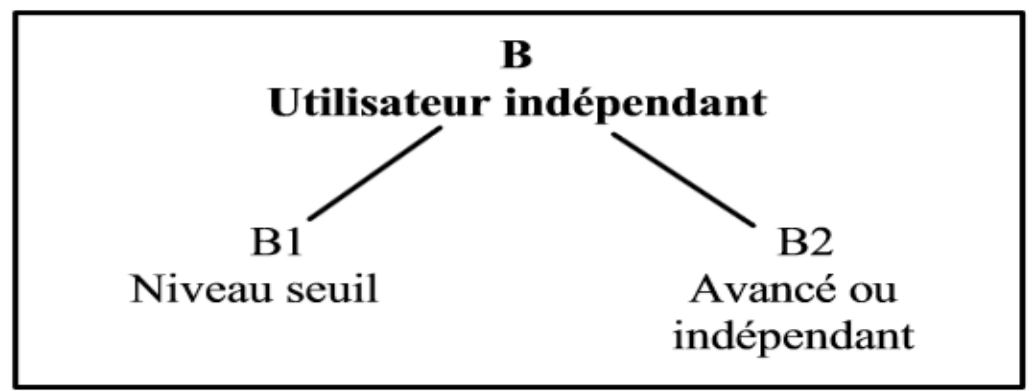

Figura 1. Articulação do Nível B

\footnotetext{
${ }^{8}$ A sigla CECRL está para Cadre Européen Commun de Réference pour les Langues ou seja, Quadro Europeu Comum de Referência para as Línguas.
} 


\section{DOSSIÊ ESPECIAL: DIDÁTICA SEM FRONTEIRAS \\ CHEREM, RAMMÉ, PEDRA \& OLMO (orgs.)}

Revista X, vol.2, 2014

\begin{tabular}{|c|c|c|c|c|}
\hline B1 & \begin{tabular}{|l}
$\mathrm{I}$ \\
$\mathrm{n}$ \\
$\mathrm{d}$ \\
$\mathrm{e}$ \\
$\mathrm{p}$ \\
$\mathrm{e}$ \\
$\mathrm{n}$
\end{tabular} & $\begin{array}{l}\text { Pode compreender os pontos } \\
\text { essenciais quando é utilizada uma } \\
\text { linguagem clara e padronizada e } \\
\text { trate-se de coisas familiares ao seu } \\
\text { trabalho, à escola, ao lazer, etc. } \\
{[\ldots]}\end{array}$ & $\begin{array}{l}\mathrm{c} \\
\mathrm{o} \\
\mathrm{m} \\
\mathrm{p} \\
\mathrm{r} \\
\mathrm{e} \\
\mathrm{e}\end{array}$ & $\begin{array}{l}\text { Eu posso compreender os textos } \\
\text { redigidos essencialmente em uma } \\
\text { língua corrente ou relativa ao meu } \\
\text { trabalho. Eu posso compreender a } \\
\text { descrição de acontecimentos, } \\
\text { expressão de sentimentos e desejos } \\
\text { em cartas pessoais. }\end{array}$ \\
\hline B2 & $\begin{array}{l}\mathrm{d} \\
\mathrm{e} \\
\mathrm{n} \\
\mathrm{t} \\
\mathrm{e}\end{array}$ & $\begin{array}{l}\text { Pode compreender o conteúdo } \\
\text { essencial de coisas concretas ou } \\
\text { abstratas em um texto complexo, } \\
{[\ldots]}\end{array}$ & $\begin{array}{l}\mathrm{n} \\
\mathrm{d} \\
\mathrm{e} \\
\mathrm{r}\end{array}$ & $\begin{array}{l}\text { Eu posso ler notícias ou relatórios } \\
\text { sobre questões contemporâneas nos } \\
\text { quais os autores adotam uma } \\
\text { atitude própria ou um certo ponto } \\
\text { de vista. }\end{array}$ \\
\hline
\end{tabular}

Tabela 1. Níveis comuns de competência B1 e B2: perfil global e tabela de autoavaliação

Neste artigo escolhemos concentrar a nossa atenção na última edição do projeto EuRom, analisando, em especial, a atividade com os materiais selecionados para o manual EuRom5, o qual compartilha com o precedente os pressupostos teóricos e os princípios operativos que, esquematicamente, podemos assim elencar:

a) A simultaneidade da aprendizagem de mais línguas;

b) Uma atenção especial para o processo da leitura: o principio operativo de base é o desfrute máximo das analogias e das transparências encontradas no interior da família das línguas românicas; a este objetivo o método oferece informações de natureza estrutural e lexical;

c) A possibilidade de transferência de estratégias de compreensão adotadas em L1 e L2 de trabalho, em um tipo de abordagem que promove a transversalidade do aprendizado e a capacidade de reinvestir a competência de compreensão escrita em qualquer língua;

d) A articulação em sessões de trabalho nas quais, para cada uma das línguas, é prevista uma atividade de escuta do texto na modalidade autêntica, a leitura silenciosa do mesmo e a tradução sintética baseada nas transparências encontradas;

e) A organização do método seja para a aprendizagem autônoma seja para a guiada; 


\section{DOSSIÊ ESPECIAL: DIDÁTICA SEM FRONTEIRAS \\ CHEREM, RAMMÉ, PEDRA \& OLMO (orgs.)}

Revista X, vol.2, 2014

EuRom5 propõe uma versão renovada e ampliada do projeto EuRom4, sobretudo por efeito da experiência de pesquisa e aplicação conduzida nos últimos quinze anos em diferentes países europeus. Os elementos de diferença são:

a) Em primeiro lugar, a introdução de uma quinta língua, o catalão, não contemplado na edição precedente. Depois de uma atenta avaliação, o acréscimo de uma outra língua foi considerado possível já que não pareceria induzir uma excessiva carga de trabalho para os aprendizes ${ }^{9}$

b) O nível de acordo com o Quadro Comum Europeu de Referência para as Línguas para o EuRom4 era B1 e para o EuRom5 fica entre o B1 e B2;

c) O número das sessões de trabalho reduzidos de 24 para 20;

d) Uma série de inovações registradas como ajuda à compreensão da leitura com indicações sistemáticas denominadas "gramática de leitura", sequências inseridas nos textos com a finalidade de oferecer informações de natureza estrutural, lexical e sugerir estratégias operativas para a compreensão ${ }^{10}$.

e) A predisposição de uma versão on-line.

A aplicação do EuRom5, o qual analisaremos, foi implementada em três fases, articuladas em 6 encontros com duração de uma hora e meia cada, desenvolvidos no Departamento de Linguística da Universidade de Roma 3. O teste foi aplicado, logo com o lançamento do manual, a 7 estudantes universitários de língua materna italiana, principiantes absolutos nas quatro línguas românicas do experimento. Os aprendizes que participaram, tiveram a oportunidade de medir simultaneamente a compreensão nas cinco línguas (incluindo a língua materna), tendo como base a leitura de artigos de jornais internacionais de média dificuldade, diferentes segundo a língua trabalhada.

A nossa reflexão é baseada nas observações de uma estudante do Curso de Graduação em Línguas e Comunicação Internacional de Roma 3, Serena Faone, coautora deste artigo, que teve a oportunidade de monitorar a atividade experimental e,

\footnotetext{
${ }^{9} \mathrm{Na}$ análise dos estudiosos poder-se-ia incluir outras línguas e dialetos românicos que poderiam ser frutíferos e interessantes. Porém, dois aspectos necessitam de uma especial atenção: o tempo para aprendizagem e o estudo da(s) língua(s) que poderia(m) ser incluída(s).

10 Para uma descrição detalhada consultar o opúsculo Références sur EuRom5: une méthode d'intercompréhension della DGLFLF (2010).
} 


\section{DOSSIÊ ESPECIAL: DIDÁTICA SEM FRONTEIRAS \\ CHEREM, RAMMÉ, PEDRA \& OLMO (orgs.)}

Revista X, vol.2, 2014

depois, desenvolveu o seu trabalho de conclusão de curso (TCC) sobre este tema ${ }^{11}$. O trabalho compreende também uma entrevista com um dos sete estudantes que fez parte do experimento ${ }^{12}$, colocando assim à disposição uma interessante compilação das reações, por parte dos aprendizes em relação à estreia do EuRom5 na sala de aula. A esses dados concretos, provenientes do foco da experiência didática, faremos referência em diversos pontos da nossa análise.

\section{APRESENTAÇÃO DE UMA ENTREVISTA EXPERIMENTAL DE EUROM5}

Nos parágrafos seguintes apresentaremos brevemente as atividades desenvolvidas no decorrer do encontro concentrando-nos sobre alguns conceitos de base que nos parecem úteis para apresentar o experimento da didática simultânea das línguas românicas em questão:

a) A dinâmica texto-contexto na entrevista de teste, que se delineia entorno da interação entre três "atores" principais, vale dizer: o aprendiz, o texto em língua estrangeira e o mediador;

b) O tipo de atividade linguística desenvolvida durante a experiência: a entrevista é articulada em três momentos principais que caracterizam também três tipos de macroatividades que, mesmo sendo estreitamente relacionadas entre si, podem ser diferentes para fins de descrição: 1) audição da gravação autêntica dos textos; 2) leitura; 3) atividade de tradução aproximativa, desenvolvida individualmente e/ou em grupos.

\section{Textos e contexto do experimento}

\section{O foco nos aprendizes}

Como dito anteriormente, os destinatários do experimento EuRom5 são sete estudantes universitários, todos de língua materna italiana. A tabela seguinte apresenta

\footnotetext{
${ }^{11}$ Faone, S. (2009). Il progetto EuRom5 - l'intercomprensione tra lingue romanze - uma sperimentazione a Roma Tre. Tesi Triennale, Università degli Studi Roma Tre.

12 As entrevistas foram também seguidas por uma estudante observadora Giulia de Santis, e Marie Pierre Escoubas Benveniste, professora de Língua Francesa na Faculdade de Economia da Universidade La Sapienzq di Roma.
} 


\section{DOSSIÊ ESPECIAL: DIDÁTICA SEM FRONTEIRAS \\ CHEREM, RAMMÉ, PEDRA \& OLMO (orgs.)}

Revista X, vol.2, 2014

alguns dados relativos aos participantes, cujos nomes aparecem indicados somente com as iniciais, a idade é entre 21 e 23 anos, são alunos de graduação e mestrado ${ }^{13}$ de humanas e exatas. $\mathrm{Na}$ tabela podemos visualizar ainda que todos os participantes conhecem a língua inglesa pelo menos em nível A2, alguns conhecem uma outra segunda língua, uma de origem românica, o francês (G.E.) e outra germânica, o alemão (R.M.). Cinco estudantes conhecem também a língua latina.

\begin{tabular}{|l|l|l|l|c|}
\hline Nome & Idade & Curso & L2 & $\begin{array}{l}\text { Conhecimento } \\
\text { do Latim }\end{array}$ \\
\hline C.F. & 21 & $\begin{array}{l}\text { Mestrado em Ciências } \\
\text { Jurídicas }\end{array}$ & Inglês B1 & $\checkmark$ \\
\hline E.M. & 23 & Graduação em Física & Inglês A2 & \\
\hline E.T. & 21 & Graduação em Letras & Inglês A2 & $\checkmark$ \\
\hline F.M. & 21 & Graduação em Letras & Inglês A2 & $\checkmark$ \\
\hline G.E. & 22 & $\begin{array}{l}\text { Mestrado em Ciências } \\
\text { Jurídicas }\end{array}$ & $\begin{array}{l}\text { Francês A2 } \\
\text { Inglês A2 }\end{array}$ \\
\hline R.M. & 23 & Graduação em Economia & $\begin{array}{l}\text { Inglês B1 } \\
\text { Alemão A2 }\end{array}$ \\
\hline V.G. & 23 & \multicolumn{2}{|l|}{ Mestrado em Biotecnologia } & \multicolumn{2}{|l|}{ Inglês A2 } & $\checkmark$ \\
\hline
\end{tabular}

A participação desses jovens no projeto é motivada pela curiosidade em relação à ideia de poder compreender mais línguas, e pelo desejo de superar a dificuldade diante de textos estrangeiros presentes em suas vidas devido a exigências profissionais. São significativas, a tal proposito, as reflexões da aprendiz entrevistada (C.F.) sobre expectativas ligadas a sua participação no experimento:

\footnotetext{
"Estava entusiasmada por fazer parte desta iniciativa porque há muito tempo queria me inscrever em um curso de língua espanhola. No futuro gostaria de trabalhar na Corte de Alicante, por isso o meu interesse era mesmo ter um primeiro contato com a língua espanhola e medir a minha compreensão nessa língua, mesmo não conhecendo nada da mesma. Fiquei encantada com a experiência, sobretudo porque pude perceber que nem todas as línguas estrangeiras são assim tão "estrangeiras". Foi uma abordagem "soft" e divertida mas sobretudo útil." (Faone 2009:66)
}

\footnotetext{
${ }^{13}$ A graduação na Itália para a maior parte dos cursos é dividida em Laurea Triennale (3 anos) e depois Laurea Magistrale (2 anos). Essa última, em alguns casos, no Brasil, seria equivalente ao nosso mestrado. Dessa forma, quando no texto aparecer a palavra Mestrado a referência é à Laurea Magistrale.

${ }^{14} \mathrm{O}$ aprendiz G.E. com o nível de Francês A2, não participou da atividade com os textos em francês.
} 


\section{DOSSIÊ ESPECIAL: DIDÁTICA SEM FRONTEIRAS \\ CHEREM, RAMMÉ, PEDRA \& OLMO (orgs.)}

Revista X, vol.2, 2014

Essas palavras evidenciam muito bem um interessante perfil motivacional do aprendiz, no qual são predominantes os componentes instrumentais e integrativos ${ }^{15}$, a notar, por exemplo, o fato de que a entrevistada enfrenta a experiência com um interesse fundamental por uma das línguas objeto do experimento, isto é, o espanhol, e encara a sua participação como uma atividade preparatória para o contato com o estudo "dedicado" deste idioma em um contexto tradicional de didática das línguas (um curso de língua) e para o projeto de uma futura inserção em um contexto de trabalho espanhol. A estudante evidencia com clareza o seu objetivo, que é aquele de ter um primeiro contato com a língua espanhola e medir a sua compreensão sem nunca ter tido uma formação "regular".

Outra componente motivacional que resulta particularmente envolvida, considerada também a especificidade do contexto didático do EuRom5, é aquela intrínseca, como mostra a consideração da nossa aprendiz entrevistada, que assim responde quando é indagada sobre o que lhe ficará da experiência vivida:

\footnotetext{
"Muitas coisas, principalmente ter encontrado estudantes que, como eu, quiseram participar em tentar compreender línguas completamente desconhecidas". [...] "Sim, é uma iniciativa muito interessante. É uma ocasião para medir você mesmo. Conseguir compreender um texto em uma língua desconhecida é uma ótima satisfação.” (Faone 2009:66)
}

Além do impulso motivacional, uma outra variação de caráter psicológicoafetivo que parece relevante no contexto experimental analisado é o comportamento que o sujeito assume em relação às línguas estrangeiras com as quais entra em contato. Ocorre, então, enfatizar que os aprendizes participam do experimento de intercompreensão levando consigo uma bagagem de conhecimento linguístico bem estruturado, vale dizer a competência da língua materna, ou seja, a língua italiana. Em relação a isso, é útil citar a noção psicotipológica proposta em 1977 por Kellerman, ou seja, a distância percebida pelo aprendiz entre a L1 e a língua de chegada, quanto ele considera esta última como instintivamente próxima ou distante. A favorecer ou inibir o

\footnotetext{
${ }^{15}$ É importante distinguir na literatura 3 tipos de componentes principais no fator motivação: a motivação instrumental, baseada na necessidade de melhorar a própria posição social e de trabalho ou de conseguir sucesso no âmbito do próprio percurso escolar; a motivação integrativa (ou integradora) fundada no desejo de inserir-se em uma comunidade de falantes; e enfim a motivação intrínseca, ligada a um interesse geral pelas línguas e à curiosidade estimulada por um particular contexto de aprendizagem (Pallotti 1998: 190-193).
} 


\section{DOSSIÊ ESPECIAL: DIDÁTICA SEM FRONTEIRAS \\ CHEREM, RAMMÉ, PEDRA \& OLMO (orgs.)}

Revista X, vol.2, 2014

transfer $^{16}$, não é somente o grau de proximidade ou distância efetiva ${ }^{17}$ entre as línguas, mas também a percepção intuitiva do aprendiz de reconhecer determinadas estruturas da L1 como potencialmente transferíveis para a língua de chegada e outras como não transferíveis.

No experimento de EuRom5 o fenômeno da "distância percebida" pode-se verificar no juízo conclusivo dos aprendizes de língua materna italiana sobre o grau de dificuldade dos textos trabalhados: muitos dos aprendizes consideraram difíceis os textos em português e catalão, mais fácil aquele em francês, mesmo sendo, o francês, a língua que está mais longe das outras línguas românicas ${ }^{18}$, enquanto admitiram com muita intensidade a transparência lexical do espanhol, o que permitiu a compreensão dos textos aplicando frequentemente simples regras de conversão lexical. Este efeito de distância entre L1-italiano e as L2 românicas de trabalho (para abreviar L2Rom) pode ser representado no seguinte modo:

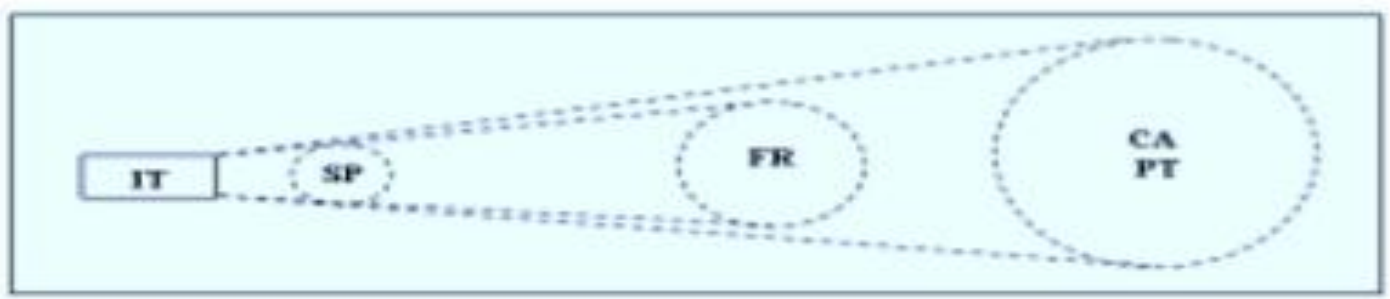

Figura 2. Distância percebida entre L1-italiano e L2Rom: início do experimento

Todavia, a percepção de maior ou menor "distância" entre as línguas parece modificar-se durante o desenvolvimento do experimento: os aprendizes descobrindo divergências sobre aparentes afinidades e semelhanças inesperadas, assim como elementos opacos, reciclaram a primeira avaliação em relação à distância entre as línguas românicas. Nas entrevistas sucessivas os entrevistadores observaram um pequeno desnível no julgamento relativo à língua francesa que começa a ser percebida como mais distante de quanto analisada inicialmente. Ao contrário, o catalão, em um

\footnotetext{
${ }^{16}$ A influência da L1 é chamada transfer linguístico, termo que indica a inteira classe de comportamentos, processos e condicionamentos imputáveis ao uso de conhecimentos linguísticos precedentes no aprendizado de uma L2 (Selinker 1992:208).

17 A ideia de proximidade ou distância entre as línguas é baseada nas considerações das relações genealógicas, tipológicas e diatópicas entre sistemas linguísticos (verificar mais informações no item 3.2).

${ }^{18}$ Simone (1997:30)
} 


\section{DOSSIÊ ESPECIAL: DIDÁTICA SEM FRONTEIRAS \\ CHEREM, RAMMÉ, PEDRA \& OLMO (orgs.)}

Revista X, vol.2, 2014

primeiro momento visto como uma língua relativamente distante foi avaliado como uma língua mais próxima ao italiano.

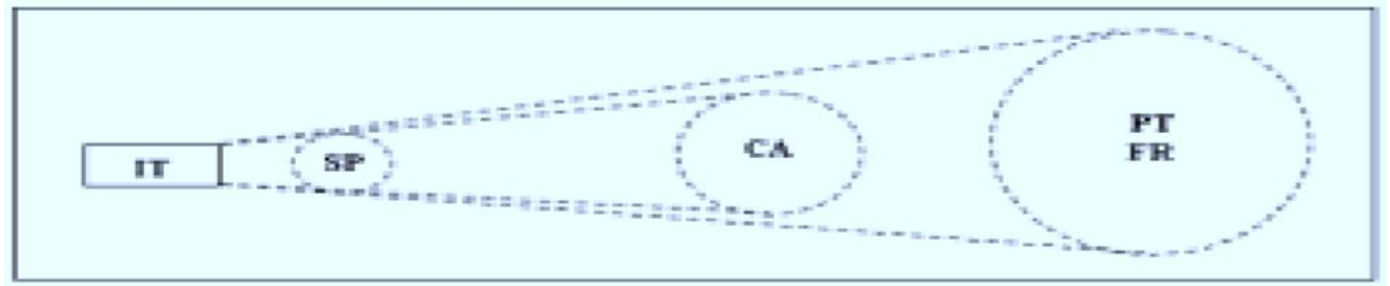

Figura 3. Distância percebida entre L1-italiano e L2Rom: fim do experimento

\section{Os textos}

O estímulo textual é a linha condutora da experiência do EuRom5, que concentra-se na habilidade de compreensão escrita. $\mathrm{O}$ encontro tem início com a distribuição aos aprendizes de cópias dos textos nas quatro línguas românicas da pesquisa. A amostra dos textos adotados responde a uma pesquisa de autenticidade e realismo nos materiais sobre os quais está baseado o experimento. Essa exigência levou à escolha de artigos de jornais e revistas extraídos da imprensa internacional mais difundidos ${ }^{19}$. O artigo de jornal aumenta a motivação dos aprendizes na leitura porque aproxima a realidade linguística de um país - repropondo várias amostras de língua no seu uso real - e apresenta uma fonte valiosa de indícios culturais. Este gênero textual segue ainda regras de redação comuns às várias línguas, apresenta conteúdos que são parte de um "saber compartilhado", e apela ao conhecimento de mundo e à experiência do aprendiz. A familiaridade com o gênero e o domínio ajudam além de antecipar as informações do texto, contribuindo à compreensão. Os temas escolhidos para a primeira fase do experimento tratam de argumentos atuais (extraídos das sessões: Atualidades, Saúde, Sociedade, Política e Economia) que agradam os aprendizes seja pela tipologia textual adotada seja pelos temas selecionados:

\footnotetext{
"Alguns extremamente divertidos, devo ser sincera. Outros muito interessantes porque colocam em contato com culturas diferentes e outros "curiosos". Lembro de forma especial de um artigo em catalão que falava de um pai que, brincando, inflou o filho com uma bomba de encher pneus. [...] Sinceramente fiquei satisfeita com os temas até agora tratados e acredito que o formato do artigo de jornal é ideal porque o estilo é mais fácil em relação àquele literário." (Faone 2009:67)
}

\footnotetext{
19 Algumas fontes foram: El Mundo, El Pais, La Vanguardia, El Periódico, Avui, Correio de Manhã, Diario de noticias, Hebdo, L'Expansion.
} 


\section{DOSSIÊ ESPECIAL: DIDÁTICA SEM FRONTEIRAS \\ CHEREM, RAMMÉ, PEDRA \& OLMO (orgs.)}

Revista X, vol.2, 2014

No interior da tipologia textual do artigo de jornal foram selecionados textos de nível adequado a aprendizes principiantes, em termos de conteúdo e complexidade linguística com o objetivo de obter a melhor relação entre a necessidade de prender a atenção e a exigência de tornar eficaz o esforço do aprendiz de elaborar e decodificar. Os textos aplicados possuem de 100 a 200 palavras ${ }^{20}$ e o insumo textual na língua estrangeira é acompanhado por uma sequência de informações contextuais expressas na língua materna do aprendiz. Em primo lugar, cada texto proposto é acompanhado pela tradução do título em italiano, em forma escrita ou fornecida em tempo real pelo aplicador/professor dos textos. Aos aprendizes é colocada ainda à disposição os seguintes instrumentos suplementares, úteis no processo da decodificação:

a) Um glossário do léxico menos acessível (por exemplo PT. Destes "di questi”, ES. Falleció "morì", CA. Guardarà "conservarà", FR. Frais "spese");

b) Tabela morfológica com as correspondências, nas várias línguas, das classes de palavras mais frequente nos textos;

c) Algumas informações de caráter enciclopédico sobre os países de língua românica.

\section{O aplicador (professor) facilitador}

Outra figura central para delinear a dinâmica interacional que caracteriza a aplicação do EuRom5 é aquela do facilitador que age como catalisador do processo de intercompreensão ativando a "reação" linguístico-cultural que acontece entre dois verdadeiros atores do encontro formativo, isto é, o aprendiz e o texto nas quatro línguas estrangeiras.

A intervenção do facilitador durante a aplicação dos textos acontece de diversas formas:

a) Gerador de expectativas: depois da audição do texto, o facilitador intervém fornecendo a tradução do título, dando assim um insumo aos alunos para antecipar o conteúdo do texto, gerando expectativas e ativando esquemas interpretativos de referência;

\footnotetext{
${ }^{20}$ O número de palavras do material foi aumentado nas fases sucessivas: entre 200 e 300 palavras na segunda fase e entre 300 e 400 palavras na terceira e última fase.
} 


\section{DOSSIÊ ESPECIAL: DIDÁTICA SEM FRONTEIRAS \\ CHEREM, RAMMÉ, PEDRA \& OLMO (orgs.)}

Revista X, vol.2, 2014

b) Foco nos elementos de correspondência entre as línguas: durante a leitura, a intervenção do facilitador é focalizada nas formas linguísticas. O objetivo é o de facilitar a superação dos obstáculos que possam existir na compreensão, encorajando quanto mais possível o recurso das transparências, analogias e regularidades entre as línguas, assim como a ativação dos processos de inferência;

c) Estratégias de avanço na leitura: durante a leitura o facilitador sugere as estratégias para adotar de forma a racionalizar o processo de compreensão promovendo a pesquisa por parte dos aprendizes e um feedback contínuo, útil à uma conscientização do processo interpretativo. Por exemplo, pede-se que se leia uma frase completa, sem que se pare em uma dificuldade; a identificar a fundamental articulação da frase em sujeito e predicado; a postergar, enfim, a decodificação de incisos e parênteses, elementos frequentemente causadores de ruídos na compreensão. $O$ facilitador encoraja a formulação de antecipações sobre o prosseguimento do texto e ajuda os aprendizes a explicitarem o conhecimento que possuem em língua materna e a utilizá-los na língua alvo. A intervenção para esclarecer eventuais problemas de léxico ou gramática não assume nunca um caráter de explicação do tipo formal, o que atrasaria a evolução individual do aluno.

O perfil do facilitador parece aproximar-se daquele de um linguista que possui competências pedagógico-didáticas e conhecimentos contrastivos nas línguas do experimento. É um mediador interlinguístico e intercultural que age "na sombra", acompanhando de modo discreto os aprendizes na experiência de intercompreensão, focalizando a atenção dos participantes sobre aquilo que pode ser útil para atingir o objetivo, mas sempre respeitando a autonomia do aluno. O seu trabalho de estímulo dos aprendizes é mais detalhado do que se pode observar em um contexto pedagógico tradicional: no experimento EuRom5 o aplicador é realmente um facilitador da aprendizagem, um construtor de modo ativo e interativo de conhecimentos e saberes, um guia capaz de exaltar as potencialidades dos aprendizes. 


\section{DOSSIÊ ESPECIAL: DIDÁTICA SEM FRONTEIRAS \\ CHEREM, RAMMÉ, PEDRA \& OLMO (orgs.)}

Revista X, vol.2, 2014

\section{As habilidades linguísticas}

\section{A escuta do texto}

$\mathrm{Na}$ fase de experimentação do EuRom5 o primeiro contato dos aprendizes com o texto acontece com a combinação da atividade de escuta e aquela de leitura. Quando se distribui o texto escrito propõe-se a escuta autêntica do texto ou a leitura em voz alta do mesmo. Além disso, os participantes, se querem, podem escutar uma parte ou todo o texto novamente. $\mathrm{O}$ envolvimento da compreensão oral é previsto principalmente nas primeiras fases para oferecer mais segurança interpretativa aos participantes, sobretudo diante às grafias de pronúncias desconhecidas, opacas à compreensão. $\mathrm{O}$ primeiro objetivo permanece porém aquele de levar o aprendiz a desenvolver a autonomia na habilidade de leitura, sem auxílio do áudio. Em todo caso, o insumo fonético-acústico fornecido durante o experimento constitui um importante elemento de suporte para elaboração de um insumo gráfico-visual, que facilita o reconhecimento dos indícios fornecidos pelo insumo escrito, guiando o aprendiz na interpretação.

O processamento do componente citado (pronúncia, sotaque, ritmo, melodia, etc) ajuda a facilitar a operação de decodificação do significado do texto, seja no nível da macroestrutura ou no da microestrutura do discurso. Constatou-se que, por exemplo, no caso de grafias distantes, a pronúncia demonstrou explícita afinidade que no plano gráfico resultam opacas. No plano fonológico, escutar o áudio melhorou a construção de "pontes mentais" de uma língua a outra, sem o recurso explicito à fonética histórica, como nas seguintes duplas de exemplo:

\section{: IT. zero ['dzero], ES.}

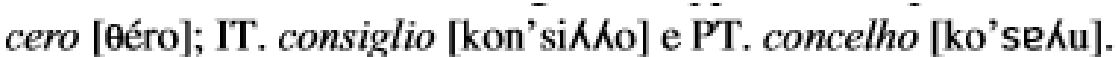

No nível sintático, embora haja diversidade de entonação das línguas tratadas, a prosódia facilitou a operação de agrupamento das palavras em unidades sintáticas (sintagmas nominais, sintagmas verbais, sintagmas adverbiais, etc.) e informativas (tema, rema, foco, etc.). Além disso, o perfil de entonação ajudou no reconhecimento do valor pragmático de cada enunciado e permitiu compreender construções complexas, como as simetrias, as comparações e os enunciados predicativos sem verbo, características do estilo argumentativo jornalístico. Um exemplo concreto é aquele 


\section{DOSSIÊ ESPECIAL: DIDÁTICA SEM FRONTEIRAS \\ CHEREM, RAMMÉ, PEDRA \& OLMO (orgs.)}

Revista X, vol.2, 2014

verificado durante a análise de um fragmento do texto espanhol intitulado Los fumadores tienen uma memoria más débil:

(1a) ES. [...] los que dejan el tabaco tienem mejores habilidades cognitivas que los que siguen enganchados.

(1b) IT. [...] coloro che smettono di fumare hanno migliori abilità cognitive rispetto a coloro che continuano ad esserne dipendenti.

Diante desse enunciado, que contém uma estrutura de tipo comparativo, os aprendizes não intuíram que a conjunção que introduzia o segundo termo de comparação. Pode-se criar a hipótese de que esse caso é devido à concorrência de vários fatores como: o escasso corpo fônico do elemento linguístico crucial (o pronome los) ou a dupla função da forma que (na primeira e na terceira ocorrência é um pronome relativo, na segunda é uma conjunção). Escutando novamente o fragmento e sobretudo prestando atenção no seguimento com a prosódia, os alunos conseguiram compreender o esquema sintático envolvido.

\begin{tabular}{|l|l|l|l|l|}
\cline { 3 - 5 } \multicolumn{2}{c|}{} & Primeiro termo de comparação & Conjunção & $\begin{array}{l}\text { Segundo termo de } \\
\text { comparação }\end{array}$ \\
\hline (1a) & ES. & $\begin{array}{l}{[\ldots] \text { los que dejan el tabaco tienen }} \\
\text { mejores habilidades cognitivas }\end{array}$ & que & $\begin{array}{l}\text { los que siguen } \\
\text { engachados. }\end{array}$ \\
\hline (1b) & IT. & $\begin{array}{l}{[\ldots] \text { coloro che smettono di fumare }} \\
\text { hanno migliori abilità cognitive }\end{array}$ & rispetto a & $\begin{array}{l}\text { coloro che continuano } \\
\text { ad essere dipendenti }\end{array}$ \\
\hline
\end{tabular}

A importância do papel da escuta varia nas diversas línguas de trabalho, confirmando as observações feitas em mérito à distância percebida (v.par.2.1.1). De modo particular, no caso do português e, sobretudo, do francês, o auxílio do áudio revelou-se de fundamental utilidade para chegar à compreensão. No caso do espanhol, ao contrário, a impressão compartilhada foi que somente o material textual era suficiente (exceto raros casos como aqueles já citados). Ao contrário, somente a gravação, na ausência do texto escrito, proposta pelo facilitador por exemplo para o breve texto em catalão, foi considerada insuficiente para alcançar a compreensão, enquanto capaz de favorecer o acesso a alguns elementos lexicais isolados.

\section{A leitura e as estratégias de compreensão}




\section{DOSSIÊ ESPECIAL: DIDÁTICA SEM FRONTEIRAS \\ CHEREM, RAMMÉ, PEDRA \& OLMO (orgs.)}

Revista X, vol.2, 2014

A leitura é a habilidade no centro da experiência de EuRom. O objetivo é levar aos aprendizes a uma compreensão global do texto submetido à leitura. Ler é uma atividade cognitiva e metacognitiva complexa que se baseia na elaboração de um insumo escrito. Mesmo tratando-se de uma atividade receptiva, no sentido em que o impulso à comunicação vem do exterior, essa pressupõe uma profunda interação entre o estímulo textual e o leitor que não é um recipiente passivo no qual convergem as informações do texto mas é um protagonista necessário e indispensável na decodificação e reconstrução do sentido desse último. Quem lê interpreta um texto projetando nesse texto os seus próprios conhecimentos enciclopédicos e representações mentais, e também ativa estratégias cognitivas em função do contexto.

Colocado de frente a um texto em língua estrangeira, o aprendiz-leitor gera, sabendo ou não, durante todo o percurso de elaboração, expectativas, na maior parte subjetivas, que refletem a evolução das suas hipóteses interpretativas em um quebracabeça de informações que vai compondo durante a leitura. Em tais expectativas confluem:

a) Conhecimentos de natureza extralinguística, ativados por antecipar em modo aproximativo o contexto do texto, acompanhado dos próprios conhecimentos de mundo e dos próprios modelos culturais;

b) Conhecimentos de natureza textual, evidenciados para prever a possível organização do texto: por exemplo na aplicação de EuRom5 os aprendizes sabem que os textos são artigos de jornais e conhecendo as convenções formais desse gênero textual esperam já um especifico modo de argumentação e construção do texto;

c) Conhecimentos de natureza metalinguística, baseados no conhecimento da língua alvo, mas também da língua materna, assim como também de outras línguas românicas e utilizados par o reconhecimento das unidades pertinentes do texto (letras do alfabeto, palavras, combinações de palavras, grupos lógicos e frases): considerado o status de principiante absoluto, é previsível que este componente seja menos desfrutado pelos aprendizes, todavia, é realmente esse o tipo de expectativa que uma abordagem como a intercompreensão almeja potenciar e promover, fazendo com que os leitores se sensibilizem às regularidades e transparências entre as línguas românicas. 


\section{DOSSIÊ ESPECIAL: DIDÁTICA SEM FRONTEIRAS \\ CHEREM, RAMMÉ, PEDRA \& OLMO (orgs.)}

Revista X, vol.2, 2014

As informações textuais e contextuais são processadas através de mecanismos inferenciais que seguem dois procedimentos de elaboração cognitiva:

a) De baixo para cima ou decodificação, que move informações tiradas do texto levando-as a um sistema de referência que consente de reconhecer o seu valor contextual;

b) De cima para baixo ou interpretação, onde é necessária a ativação de um esquema de referência para ajudar o leitor a resolver ambiguidades criadas por mais interpretações plausíveis.

Uma das preocupações presentes no experimento foi aquela de acostumar os aprendizes a utilizar conscientemente mais estratégias cognitivas de leitura para alcançar a compreensão. Os aprendizes se valeram em medidas diferentes das várias técnicas, confiando inicialmente na transparência lexical (sobretudo os aprendizes mais inseguros), e depois no contexto linguístico, nos conhecimentos extralinguísticos e na semelhança sintática.

Em relação aos processos de elaboração das formas das palavras, é significativo o caso do aprendiz C que, a partir da observação de que a língua portuguesa pode-se contrair preposição e determinante (PT. destes $=d e+e s t e s ~ ' d i+q u e s t i ', d a s=d e+a s$ ' $d i+l e$ '), por analogia estendeu esta regra gramatical hipnotizando que no pudesse significar ' $n e l=i n+i l$ ' mesmo com a interferência da partícula de negação na L1 (non). Por outro lado, a importância das estratégias de alto, como aquelas induzidas da tradução do título do texto, é evidente no caso da interpretação do referente nominal português os bombeiros (ES. bombeiros, IT. pompieri/vigili del fuoco) na frase Uma criança de sexo masculino nasceu hoje, cerca das $12 \mathrm{~h} 00$, numa ambulância dos bombeiros de Resende ('Un bambino di sesso maschile, è nato oggi, intorno alle 12, in una ambulanza, dei pompiei di Resende'). Em um contexto como aquele do parto em ambulância no qual os aprendizes italianos esperam a presença de médicos ou enfermeiros, a compreensão falha pela falta da ativação dos modelos de interpretação apropriados, do memento em que na França e em Portugal existe um diferente hábito cultural. A intervenção da integração dessa informação pelo professor/facilitador remete imediatamente à interpretação correta. 


\section{DOSSIÊ ESPECIAL: DIDÁTICA SEM FRONTEIRAS \\ CHEREM, RAMMÉ, PEDRA \& OLMO (orgs.)}

Revista X, vol.2, 2014

\section{O processo de tradução}

A tradução é presente nos encontros experimentais em dois diferentes momentos: na fase do primeiro contato com o texto, quando o facilitador traduz o título e durante o processo de leitura como atividade da qual são protagonistas os alunos. No método EuRom5 a tradução oral dos textos propostos representa um meio para indagar e explicitar as estratégias de compreensão ativadas pelos aprendizes e verificar as intuições, inferências e hipóteses deles. Durante os encontros experimentais, o facilitador propôs aos discentes a utilização da técnica do 'thinking aloud' ou 'pensar em voz alta', cujos resultados - recolhidos com um gravador - permitiram a monitoração das operações mentais que os conduziram à compreensão. O processo de tradução não é linear, pelo contrário, articula-se nas seguintes etapas:

a) Tradução aproximativa: presente o direito ao erro e ao emprego de palavras vazias coisa (para os nomes) e coisar (para os verbos);

b) Retomada da tradução: admite reflexões sobre a tradução efetuada e prevê a compreensão das palavras e dos segmentos textuais não traduzidos precedentemente;

c) Reconstrução da frase e do período.

A título exemplificativo propomos em seguida o trabalho de tradução de um fragmento do texto em português intitulado Criança nasceu em ambulância a caminho de Viseu, feito pelos aprendizes, ilustrando as três fases do trabalho de tradução mencionado:

(2a) PT. Desde que a maternidade do Hospital de Lamego - a mais próxima de Resende - encerrou, há cerca de um ano, os Bombeiros Voluntários locais já deram assistência a cinco partos [...]

(2b) IT. Da quando il reparto maternità dell'Ospedale di Lamego - il più vicino a Resende - chiuse un anno fa, i Pompieri Volontari locali hanno dato assistenza già a cinque parti $[\ldots]$ 


\section{DOSSIÊ ESPECIAL: DIDÁTICA SEM FRONTEIRAS \\ CHEREM, RAMMÉ, PEDRA \& OLMO (orgs.)}

Revista X, vol.2, 2014

a) Primeira fase: os aprendizes propuseram uma primeira tradução incompleta, substituindo a expressão desde que e o verbo encerrou com palavras vazias e "pulando" a tradução do trecho - a mais próxima de Rezende -;

b) Segunda fase: traduziram bem a frase subordinada introduzida por desde que e formulou duas hipóteses interpretativas - ambas plausíveis - em relação ao significado da incógnita lexical encerrou (que não existiam leitos disponíveis na ala de maternidade ou que estava fechada). Retomando a tradução do trecho $a$ mais próxima de Resende os alunos realizaram uma tradução 'decalque' a mais próxima a Resende (ao invés de a mais vicina a Resende);

c) Terceira fase: as características formais do termo encerrou e o contexto linguístico convenceram os alunos da validade da suas segundas hipóteses, traduzindo enfim corretamente o trecho.

\section{A centralidade do léxico}

O nível linguístico no qual é mais comum as transparências entre as línguas românicas é com certeza o nível lexical. Nessas línguas, existe uma ampla possibilidade que as identificações interlinguísticas demonstrem-se corretas, de forma especial graças à semelhança formal das palavras, sobretudo aquelas que pertencem à esfera intelectual e política e que fazem parte do Standard Average European ${ }^{21}$.

O conhecimento do léxico da L2 dos aprendizes de EuRom5 é inicialmente potencial, isto é, inerente àquelas palavras que reconhecem sem nunca tê-las encontrado antes, porque pertencem a um domínio familiar ou aparecem em várias línguas da mesma forma. Somente quando os aprendizes colhem os parentescos existentes, podem tentar reconstruir de maneira intuitiva um léxico transversal entre as línguas o que ajuda substancialmente a compreensão. O objetivo de EuRom5 é o desenvolvimento de um léxico passivo, constituído pelas palavras que os aprendizes não usam mas conhecem. ${ }^{22}$

Na primeira fase experimental o processo de compreensão do texto está centrado na decodificação e interpretação das palavras conteúdo. Verificou-se então que os erros

\footnotetext{
${ }^{21}$ Com esse termo Benjamim Lee Whorf indicava a semelhança gramatical, compartilhada pelas maiores línguas europeias. O conceito foi posteriormente retomado pelo linguista Paolo Ramat, segundo o qual, além da afinidade estrutural, as línguas da Europa centro-ocidental formam uma koiné na qual "o fenômeno de afinidade mais macroscopicamente evidente [...] é composto pelo léxico intelectual, pelos termos abstratos construídos com técnicas com base no modelo greco-latino”. (cit. in. Bonvino 1998:272) ${ }^{22}$ Cfr. Bettoni (2001:67).
} 


\section{DOSSIÊ ESPECIAL: DIDÁTICA SEM FRONTEIRAS \\ CHEREM, RAMMÉ, PEDRA \& OLMO (orgs.)}

Revista X, vol.2, 2014

lexicais tiveram uma incidência predominante no processo de compreensão. A percepção do grau de dificuldade de compreensão do léxico varia de aprendiz para aprendiz. Apesar disso, é possível identificar alguns aspectos objetivos que geralmente tornam mais ou menos difíceis o processo de compreensão de uma palavra conteúdo ou de uma expressão em uma segunda língua. Alguns critérios de relevância na dificuldade ou facilidade de compreensão são: o tamanho, se é visto por exemplo que, talvez para um princípio cognitivo de caráter icônico, os aprendizes tiveram dificuldades a elaborar os monossílabos (por exemplo PT. cos/IT. corpo; CA. cap/IT. nessuno; ES. tras/IT. dopo, dietro); a frequência de ocorrência das palavras nos textos propostos e os seus campos de extensão, ou seja o número dos textos nos quais aparecem; o campo semântico ao qual pertence as palavras; a fraseologia e a polissemia.

Nos primeiros contatos com as línguas românicas os aprendizes são levados ao conhecimento preliminar na língua materna, ponto de referência constante para reconhecer as transparências lexicais e formular hipóteses interpretativas válidas. A L1 representa para os aprendizes principiantes a chave de acesso às outras línguas românicas, guia o percurso deles e influencia a compreensão através do transfer linguístico. Por outro lado, parece evidente que a estratégia de recorrer à comum etimologia implica uma reflexão sobre a própria língua e uma tomada de consciência metalinguística de notável interesse.

Verificou-se também, que com a finalidade de decodificação do insumo textual foi muito útil também o conhecimento da língua inglesa e dos dialetos regionais (ES. Papel/ING. Paper, CA. Desenvolupament/INGL. Development, FR. Travail/D. Sicil. Travagliu, PT. carretera/IT. carreggiata). Porém, a excessiva confiança na plena correspondência gráfica e semântica entre a L1 e a L2 levou, em alguns casos, o aprendiz a acreditar em semelhanças enganadoras, os "falsos cognatos" (por exemplo FR.confiance/IT.fiducia; ES.primo/IT.cugino; CA. poblacions/IT.quartieri; PT.dono/IT. padrone). De qualquer forma, a frequência de transfers negativos devido aos falsos cognatos foi inferior àquela prevista, isto porque os aprendizes conseguiram identificar as ambiguidades semânticas fazendo uso de uma adequada contextualização.

Durante os encontros, de fato, revelou-se que na compreensão das unidades semânticas prevaleceu o valor pragmático da palavra em relação à análise morfológica e sintática. Isso aconteceu porque as palavras não eram percebidas isoladamente: seja o contexto imediato, ou melhor, o conjunto dos elementos da frase já interpretados, seja o 


\section{DOSSIÊ ESPECIAL: DIDÁTICA SEM FRONTEIRAS \\ CHEREM, RAMMÉ, PEDRA \& OLMO (orgs.)}

Revista X, vol.2, 2014

contexto mais amplo, o tema geral tratado no texto reduzia múltiplas possibilidades de interpretações semânticas avançadas. Somente em um segundo momento os alunos notavam as propriedades estruturais do termo em questão filtrando, ulteriormente, as próprias hipóteses. Vale a pena destacar que as informações contextuais não se esgotam somente em termos estreitamente linguísticos. Para o aprendiz que encontra problemas de compreensão, o insumo mais facilmente decifrável é aquele no qual o equilíbrio entre a informação extralinguística e aquela linguística é balanceado a favor do contexto de conhecimento empírico. No caso do texto catalão Enterrem em uma capsa de patates Pringles les cendres del seu dissenyador os aprendizes traduziram facilmente os termos embolcall rodó (IT. custodia rotonda) mesmo não sendo transparentes, graças ao próprio saber enciclopédico. Se não tivesse sido evidenciada aos aprendizes a inconfundível embalagem cilíndrica das batatinhas Pringles, vendidas também na Itália, a interpretação dos dois vocábulos resultaria obscura. Se um texto é culturalmente próximo ao aprendiz, o leitor pode valer-se dos seus conhecimentos de mundo para inferir sobre o conteúdo, redimensionando de tal forma uma dificuldade linguística. Todavia, confiar em informações extralinguísticas pode-se revelar enganoso se o ambiente é culturalmente opaco, mesmo no caso no qual o insumo fornecido tenha uma boa relação contextual. De fato, aquilo que é côngruo ou plausível em uma cultura pode não ser necessariamente em outra. Por exemplo, como já dito anteriormente (confrontar item 2.2.2), no texto português os aprendizes intuíram corretamente que tratava-se da reportagem de um parto ocorrido dentro de uma ambulância, portanto esperam a presença de enfermeiros e não de bombeiros "pompieri" termo que não conseguem interpretar por causa de uma diferença sociocultural.

\section{ANOTAÇÕES PARA UMA REFLEXÃO EPISTEMOLÓGICA SOBRE A IC}

Nas sessões seguintes queremos apresentar algumas considerações de natureza pistemológica sobre a estrutura formal do âmbito de conhecimento científico que podemos designar com a etiqueta intercompreensão. Retomando a articulação conceitual evidenciada na abertura do parágrafo 1.1 na definição de epistemologia, as nossas reflexões podem ser agrupadas nos seguintes pontos:

a) Linguagem: definições e conceitos de intercompreensão; o caráter transversal da noção de intercompreensão; 


\title{
DOSSIÊ ESPECIAL: DIDÁTICA SEM FRONTEIRAS \\ CHEREM, RAMMÉ, PEDRA \& OLMO (orgs.)
}

Revista X, vol.2, 2014

b) Método: a intercompreensão como objeto de pesquisa linguística;

c) Organização interna: didática tradicional e didática plurilíngue;

d) Resultados: a intercompreensão como habilidade linguística.

\section{Sobre a linguagem da IC}

Quanto à questão da terminologia nos estudos sobre a intercompreensão, é importante partir das palavras de Marie-Christine Jamet (2010) ${ }^{23}$ que, baseando-se nas análises de fontes lexicográficas e científicas, observa que:

\begin{abstract}
«(...) plus le champ de recherche suscite d'intérêt, au-delà des langues romanes qui ont été pionnières, (...) plus on a l'impression que certaines discussions naissent tout simplement du fait que les chercheurs ne parlent pas exactement un terme que la linguistique utilisait dans les recherches en dialectologie pour tracer les limites géographiques des aires dialectales, s'est étendu aux familles de langues, et bascule de la linguistique à la didactique des langues. »
\end{abstract}

A primeira consideração é referente ao fato de que nos discursos dos pesquisadores, o termo intercompreensão parece evocar diversas referências conceituais. Em segundo lugar, revela-se uma interessante evolução no uso do termo, que passa do âmbito da disciplina linguística da dialetologia, onde atuava na discriminação das fronteiras, e portanto das diferenças, entre diversas zonas dialetais, ao setor disciplinar da didática das línguas com uma acepção que enfatiza, ao contrário, a pesquisa das afinidades entre sistemas linguísticos. Neste âmbito, destaca a estudiosa (ibidem), é apreciada, além do mais, a contínua oscilação do termo entre as duas disciplinas mencionadas: linguística e didática.

A inerente polissemia do termo não faz senão espelhar, ao nosso ver, um estágio de constante evolução dos limites do campo da pesquisa, no qual o conceito de intercompreensão encontra-se a reagir às várias declinações de uso com as quais circula na comunidade cientifica, que o desenvolve, o completa, o adapta, o modifica, associando-o a diversas referências (Depecker 1999:21). Em outras palavras, existe a impressão de que ainda não se foi estabelecido um objeto comum de pesquisa mas que prevalece a imagem de que a singular prospectiva de estudo propõe. Por outro lado, essa deformação contínua da noção de intercompreensão é sintomática do caráter inerentemente transversal da categoria conceitual que se encontra no ponto de

\footnotetext{
${ }^{23}$ Clara Ferrão Tavares (2007) conduziu um estudo lexicométrico do termo intercompreensão em um corpus constituído por diversos números da revista Etudes de linguistique appliquée a partire dal 1990 (cit. in Jamet 2010).
} 


\section{DOSSIÊ ESPECIAL: DIDÁTICA SEM FRONTEIRAS \\ CHEREM, RAMMÉ, PEDRA \& OLMO (orgs.)}

Revista X, vol.2, 2014

intersecção entre o estudo da comunicação através de sistemas de signos (semiótica), o estudo das línguas verbais (a linguística), o estudo da variação linguística (a tipologia linguística, a linguística diacrônica, a sociolinguística, a linguística espacial), a didática das línguas e a política linguística.

\section{O método na IC}

O âmbito cientifico da intercompreensão pode ser colocado no interior da linguística aplicada, em especial, na didática (v. par. 1.2), focalizada na pesquisa de dois fundamentais processos de aprendizagem/aquisição por parte do aprendiz e do ensinamento das línguas estrangeiras. O saber científico sobre o qual está estruturada a ciência da intercompreensão é portanto de tipo eminentemente linguístico e é na linguística que nascem as raízes metodológicas desse novo setor do conhecimento.

De particular relevância na caracterização da metodologia aparece, segundo a nossa visão, o conceito de variação linguística. Na intercompreensão, parecem, de fato, fundirem-se duas diferentes perspectivas sobre o fenômeno da variação entre línguas: de um lado aquela própria da tipologia linguística, atenta a colher as afinidades na gama de variações observáveis em sincronia entre as línguas, e por outro lado aquela própria da linguística diacrônica, que encontra os laços de parentesco genético entre essas. Pela síntese dessas duas prospectivas emerge com força a ideia de graus nas propriedades das línguas. A ideia de um continuum de variação ao longo do qual se dispõem as variantes pode ser analisada também pelo ponto de vista do sujeito envolvido na aprendizagem, elaborando, posteriormente a noção de distância percebida. Como observamos anteriormente (v. par. 2.2.1) a variável L1 tem um poder predominante no processo de intercompreensão no determinar a percepção de proximidade/distância das línguas estrangeiras. A partir do momento em que a intercompreensão tem como objetivo a aquisição da habilidade de compreender mais línguas românicas, seria interessante explicitar, em chave tipológica, a natureza do condicionamento exercitado pela L1 de partida: português, espanhol, catalão, francês ou italiano. Vimos, de fato, que os aprendizes italianos observados no experimento de EuRom5 percebem globalmente os textos escritos em espanhol como mais fáceis de compreender enquanto demonstram maior dificuldade na intercompreensão de textos portugueses, mas sobretudo daqueles em catalão e em francês. Considerando essas informações seria desejável explorar as 


\section{DOSSIÊ ESPECIAL: DIDÁTICA SEM FRONTEIRAS \\ CHEREM, RAMMÉ, PEDRA \& OLMO (orgs.)}

Revista X, vol.2, 2014

implicações metodológicas do parâmetro que poderíamos definir da direção no processo de intercompreensão, o qual possui a sua gênese na centralidade da L1. Nesse sentido, ao lado da noção de intercompreensão poderíamos falar de específicos tipos de intercompreensão como os arrolados a seguir:
a) IC L1 IT.: Intercompreensão com italiano como L1;
b) IC L1 ES.: Intercompreensão com espanhol como L1;
c) IC L1 PT.: Intercompreensão com português como L1;
d) IC L1 CA.: Intercompreensão com catalão como L1;
e) IC L1 FR.: Intercompreensão com francês como L1;

A seguir, propomos uma representação gráfica do parâmetro da direção:

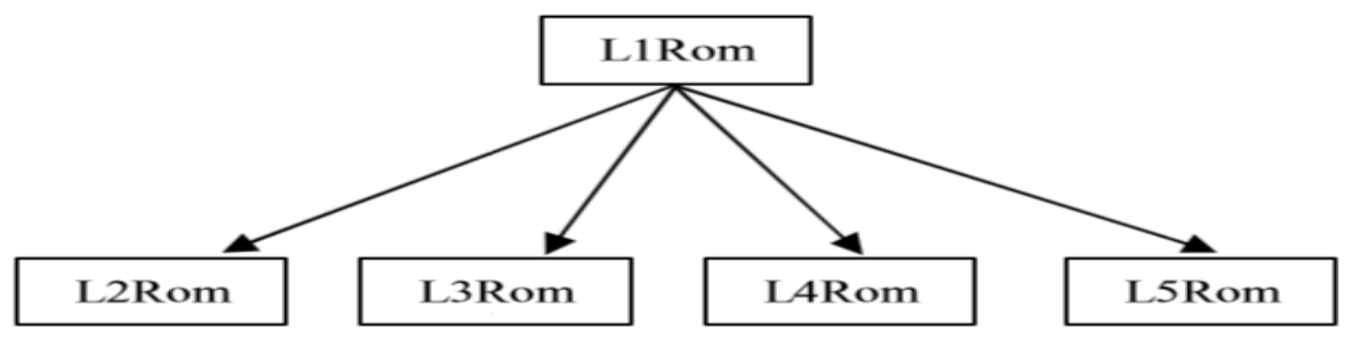

Figura 4. O parâmetro da direção no processo da intercompreensão

Com base nessa articulação pode-se delinear uma espécie de tipologia receptiva das línguas românicas que poderia permitir colocar em um continuum os diferenciais de dificuldade entre a L1 predominante e as outras línguas de trabalho. Essa informação permitiria aperfeiçoar a criação dos métodos de ensino/aprendizagem simultâneos das línguas, desenvolvendo soluções ad hoc de acordo com os diferentes perfis das L1, indiscutivelmente o elo do processo de intercompreensão.

Resumindo, uma das prioridades relativas às definições da engrenagem metodológica das pesquisas em intercompreensão é, ao nosso ver, a necessidade de aprofundar e explicitar as bases linguísticas deste setor de pesquisa. A nossa convicção sobre o assunto é que provavelmente a disciplina que mais diretamente está relacionada ao campo da pesquisa da intercompreensão e da qual poderia atingir para definir a própria ordem, os próprios instrumentos metodológicos é a tipologia linguística. A tal propósito, seria interessante considerar a aplicação ao estudo da intercompreensão de conceitos da linguística tipológica, como aqueles de universal linguístico, hierarquia 


\section{DOSSIÊ ESPECIAL: DIDÁTICA SEM FRONTEIRAS \\ CHEREM, RAMMÉ, PEDRA \& OLMO (orgs.)}

Revista X, vol.2, 2014

implicacional de traços distintivos, além da noção de continuum já sugerida (Comrie 1983).

\section{A relação entre didática plurilíngue e didática tradicional: reflexões de um hispanista}

No experimento de EuRom5 procurou-se em promover a competência dos aprendizes a encontrar e desfrutar ao máximo, com fins de compreensão, os aspectos de afinidade e as transparências entre as línguas da família românica. Essa forma de conduzir o ensino das línguas estrangeiras pode ser utilmente integrada na didática tradicional, não simultânea, como estratégia que estimula a aprender a ver as diferenças e as diversidades sempre do fundo de um terreno comum de semelhanças e proximidades. De fato, as oposições e as distinções podem ser concebidas e admiradas somente sob observação da existência de um elemento de continuum (Jakobson 1963). Os aspectos diferenciais e de afinidade deveriam ser mais utilmente percebidos como duas faces da mesma moeda, sendo bem presente também na didática tradicional das línguas estrangeiras, tipicamente centrada na apresentação das especificidades de uma língua estudada. Particularmente, a abordagem da intercompreensão presta-se a caracterizar a primeira fase do processo de aprendizagem de uma língua estrangeira. Nessa sessão nos referimos à atividade experimental do Eurom5 em Roma 3, concentrando-nos somente na parte relativa ao trabalho conduzido com o texto em língua espanhola, procurando fazer considerações, do ponto de vista de um hispanista sobre a possibilidade de conjugar na prática didática a "linguística dos contrastes" ou contrastiva com a "linguística das transparências" evocada pela ideia de intercompreensão.

\section{Los fumadores tienen una memoria más débil. I fumatori hanno una memoria più debole.}

1. Varios estudios han señalado que le tabaco es un

2. factor de riesgo para la demencia, pero ahora un

3. trabajo constata que fumar hace que la memoria

4. se risienta. Un equipo del Instituto Nacional de 


\section{DOSSIÊ ESPECIAL: DIDÁTICA SEM FRONTEIRAS \\ CHEREM, RAMMÉ, PEDRA \& OLMO (orgs.)}

Revista X, vol.2, 2014

5. Salud e Investigación de Villejuif

6. (Francia) ha llegado a la conclusión tras

7. realizar un seguimento durante 17 años a más

8. de 10.000 funcionarios británicos que, al inicio

9. del estudio, tenían edades comprendidas entre

10. los 35 y los 55 años. Tal y como publica Archives

11. of Internal Medicine, además de un registro de

12. sus hábitos, los partecipantes completaron

13. periódicamente varios tests de memoria,

14. razionamiento, vocabulario y fluidez verbal. Parte

15. de los individuos analizados falleció durante la

16. recopilación de los datos o abandonó la

17. investigación, por lo que, finalmente, los

18. investigadores manejaron a un total

19. de 4.659 personas. Los resultados monstraron que

20. los fumadores tenían peor memoria y

21. habilidades de razonamiento que los que no

22. habían probado un pitillo en su vida. No

23. obstante, los autores, confirman que los daños no

24. son irreversibiles. Los que dejan el tabaco tienen

25. mejores habilidades cognitivas que los que

26. siguen enganchados.

Tratto da EI Mundo, 14.06.2008 (181 parole)

Tabela 4. O texto Espanhol

$\mathrm{Na}$ atividade experimental a tradução do primeiro fragmento do texto espanhol, aqui apresentado, foi feita por F. sem problemas: intuiu o significado da palavra trabajo, em italiano lavoro, (linha 3). Também C. também inferiu o significado devido a transparência gráfica com o dialeto siciliano travagliu. $\mathrm{O}$ facilitador acrescentou que a palavra tras (linha 6), traduzida pelo aprendiz como tramite (por meio de), significa na realidade dopo (depois). É importante evidenciar que o erro é provavelmente fruto de um transfer negativo da L1, mas de qualquer forma não influenciou de maneira decisiva a compreensão. No segundo fragmento o aprendiz E. fez uma exata e rápida tradução da 


\section{DOSSIÊ ESPECIAL: DIDÁTICA SEM FRONTEIRAS \\ CHEREM, RAMMÉ, PEDRA \& OLMO (orgs.)}

Revista X, vol.2, 2014

frase principal. O facilitador forneceu somente a tradução de además "oltre a" (linha 1). E relação à palavra hábitos "abitudini” (linha 12), G. entendeu que se tratava de um substantivo masculino plural, mas interpretou erroneamente o significado, propondo inicialmente abitanti (habitantes), talvez baseando-se no contexto precedente que falava da população. No fragmento seguinte, o facilitador forneceu a tradução do verbo falleció "morì" (linha 15), sendo esse fator de forte interferência com o verbo italiano fallire e também de por lo que "per cui" (linha 17), estruturalmente pouco transparente. No restante do texto não foi identificada nenhuma dificuldade, com exceção das dúvidas iniciais em relação à conjunção que "che" (linha 21), a qual introduzia o segundo termo de comparação los que siguen enganchados "coloro che continuano ad esserne dipendenti" (linha 25-26). Depois de escutar o fragmento o resultado tornou-se compreensível (v. par. 2.2.1).

Essas evidências, dedicadas ao espanhol, evidenciam o alto grau de “intercompreensão natural” entre a L1 italiana e a L2 espanhola, evidenciado também a opinião unânime do grupo de aprendizes sobre a facilidade de atingir uma melhor compreensão global deste texto em relação ao das outras línguas. A efetiva compreensão do texto em espanhol realiza-se devido à elevada transparência morfológica e lexical (a forma das várias classes de palavras e as suas regularidades combinatórias) e sobre a substancial correspondência no modo de distribuir e organizar a informação no interior das frases e de forma geral no discurso (a ordem dos constituintes é muito semelhante àquela do italiano). Todavia, as intervenções do facilitador e as hipóteses erradas dos aprendizes marcam algumas áreas de dificuldade para os italianos, principiantes ou não, quando a compreensão tropeça fazendo perder a fluidez do texto. Essas zonas opacas apresentam os fenômenos de "diferença fim", que implicam em um distanciamento sutil entre as línguas em uma área maior de consistente afinidade. São exatamente esses pontos que a didática tradicional "não simultânea" dedicada ao aprofundamento das especificidades da língua espanhola, pode ir no caminho da intercompreensão.

Consideramos, por exemplo, o caso de tras no trecho Um equipo del Instituto Nacional de Salud e Investigación médica de Villejuif (Francia) ha llegado a la conclusión tras realizar un seguimiento durante 17 años a más de 10.000 funcionarios britânicos (linhas 4-8). O aprendiz traduz tras como tramite não só pela semelhança com a palavra italiana mas provavelmente também porque intui a relação 


\section{DOSSIÊ ESPECIAL: DIDÁTICA SEM FRONTEIRAS \\ CHEREM, RAMMÉ, PEDRA \& OLMO (orgs.)}

Revista X, vol.2, 2014

instrumento/fim com a conclusão atingida pelos cientistas. Todavia, é importante ressaltar um elemento de diferença entre as línguas que pode ter desorientado os aprendizes, ou seja, a combinação de tras realizar com a presença do infinitivo simples depois da preposição tras, já que em italiano é necessário um infinitivo composto (dopo aver condotto).

Também, mais adiante, no trecho además de un registro de sus hábitos (linhas 11-12), a compreensão foi concluída com a correspondência pontual na qual a semelhança lexical com o italiano hábitos ("abitudini" e non "abitanti”) combina-se com a presença e uma unidade linguística opaca, que é novamente um elemento de conexão, um conector de adição además de "oltre a", o qual significado, não por acaso, é fornecido pelo facilitador. Enfim, também a terceira intervenção de tradução do facilitador refere-se ainda a um elemento relacional, a conjunção consecutiva por lo que (linha 17). Na parte final do texto, o processo de compreensão conclui-se na elaboração do segundo termo de comparação da estrutura comparativa: a releitura dissolve a dúvida, concentrando-se no valor do que, provavelmente pouco saliente do ponto de vista fônico na sequência que los que siguem enganchados. De toda forma, também essa dificuldade é inerente a um inexato reconhecimento de um elemento de conexão no interior da construção de comparação (em italiano faz-se necessária a preposição di ou ainda a locução rispetto $a$ ).

A análise do texto espanhol desperta a atenção dos aprendizes para as fortes semelhanças que são necessárias notar, mas também, ao mesmo tempo, evidencia alguns pontos de fratura entre os dois sistemas linguísticos: o texto usado no experimento permite observar que se o fundamental "lugar" de transparência para os italianos é o léxico, as unidades de conexão sintática e discursiva (preposições e conectores textuais), a microssintaxe das cominações de palavras (ex. tras realizar) e a recognição de construções sintáticas especiais (es. a frase comparativa) como esquemas de distribuição da informação do enunciado. Estas áreas de "gramática fim" podem ser utilizadas para aprofundar aspectos específicos de cada língua em um percurso que se move do transparente em direção ao opaco, daquilo que é comum para o que é diferente, e não o contrário. 


\section{DOSSIÊ ESPECIAL: DIDÁTICA SEM FRONTEIRAS \\ CHEREM, RAMMÉ, PEDRA \& OLMO (orgs.)}

Revista X, vol.2, 2014

\section{A IC entre as habilidades do aprendiz}

A intercompreensão pode ser considerada um particular tipo de habilidade ou competência na comunicação linguística. Em referência a isso, é interessante verificar como esta visão de intercompreensão coloca-se no quadro oficial da descrição das quatro habilidades linguísticas reconhecidas pelo Quadro Comum Europeu de Referência para o ensino das Línguas (CECRL, 2001:18):

a) Recepção (escrita e/ou oral);

b) Produção (escrita e/ou oral);

c) Interação (escrita e/ou oral);

d) Mediação (escrita e/ou oral);

A intercompreensão é sem dúvida enquadrada como uma habilidade do tipo interativa, relacionada a uma troca entre falantes de línguas diferentes (aparentadas ou não) e não com uma genérica situação de confronto comunicativo:

\footnotetext{
"Dans l'interaction, au moins deux acteurs participent à un échange oral et/ou écrit et alternent les moments de production et de réception qui peuvent même se chevaucher dans les échanges oraux. Non seulement deux interlocuteurs sont en mesure de se parler mais ils peuvent simultanément s'écouter. Même lorsque les tours de parole sont strictement respectés, l'auditeur est généralement en train d'anticiper sur la suite du message et de préparer une réponse. Ainsi, apprendre à interagir suppose plus que d'apprendre à recevoir et à produire des énoncés. On accorde généralement une grande importance à l'interaction dans l'usage et l'apprentissage de la langue étant donné le rôle central qu'elle joue dans la communication". (CECRL $2001: 18$ )
}

É importante dizer que a descrição anterior mostra, na forma como é expressa, um modelo ideal de intercompreensão que não encontra plena resposta no plano da realidade das práticas didáticas. Como destaca Jamet (2005:117): “as primeiras experiências no setor - EuRom 4, Galatea, EuroComRom para as línguas românicas privilegiaram de forma maciça um único tipo de situação comunicativa: o uso do canal escrito, o não compartilhamento das mesmas coordenadas espaço-temporais existindo uma ausência de interação". A nossa opinião é de que seja importante reconhecer a especificidade do processo interativo que existe na intercompreensão escrita, onde o sujeito se confronta com uma mensagem (o texto) que representa o produto de um ato enunciativo que deve ser reconstruído em seguida, desfrutando de todos os indícios textuais e contextuais à disposição. Sendo assim, seria útil explicitar na descrição da atividade de interação codificada no Quadro de Referências a distinção entre: 


\section{DOSSIÊ ESPECIAL: DIDÁTICA SEM FRONTEIRAS \\ CHEREM, RAMMÉ, PEDRA \& OLMO (orgs.)}

Revista X, vol.2, 2014

a) Dois tipos de interação: 1) entre falantes de uma mesma L1;2) entre falantes de diferentes L1 (na modalidade intercompreensão, as línguas simultaneamente envolvidas podem ser mais de duas);

b) Três tipos de intercompreensão: 1) escrita; 2) oral e 3) escrita e oral ao mesmo tempo.

\section{CONCLUSÕES}

Neste trabalho propusemos algumas considerações epistemológicas sobre um setor de pesquisa científica particularmente atual e em via de definição, que gira em torno da noção de intercompreensão. Para alcançar esse objetivo desenvolvemos o nosso raciocínio servindo-nos de um percurso heurístico especial, que parte da prática da experimentação de um projeto de didática inspirada na intercompreensão (EuRom5) para fazer observações de ordem epistemológica sobre esse âmbito de estudo.

A escolha de participar da aplicação didática evidencia, de um lado, a centralidade da dimensão didática sobre a intercompreensão na sociedade atual, que iniciou a perceber de modo agudo o valor estratégico da educação linguística em um contexto plurilíngue. Por outro lado, a descrição da fase de experimentação em classe da nova versão do método EuRom em vista da sua publicação, leva a refletir sobre uma das fases caracterizadoras do processo científico, de fato, aquela da experimentação, aprofundando, além disso, a observação através do instrumento da entrevista com um dos aprendizes diretamente envolvido no experimento.

A primeira consideração refere-se à dificuldade de definir a intercompreensão. A adaptabilidade do termo se conjuga de fato a uma extrema dinamicidade do conceito que determina um objeto diferente de acordo com a prospectiva adotada. Esta propriedade coloca em evidencia a transversabilidade da noção de intercompreensão que se coloca diante de vários âmbitos disciplinares e pode ser vista em vários níveis de abstração, a enfatizar o fato que trata-se de um objeto de pesquisa e de uma disciplina científica que está sendo definida e solidificada. A tal propósito observa-se como expomos neste artigo o uso do termo oscilante entre as seguintes acepções: passos ou fenômeno comunicativo, habilidade linguística, competência parcial e aproximativa, objeto de pesquisa científica, processo, habilidade de tipo interativo, modalidade comunicativa, comportamento de conhecimento, forma de metaconhecimento. 


\section{DOSSIÊ ESPECIAL: DIDÁTICA SEM FRONTEIRAS \\ CHEREM, RAMMÉ, PEDRA \& OLMO (orgs.)}

Revista X, vol.2, 2014

Se a caracterização sociocultural predominante na intercompreensão é de tipo educativo, a "substância", os conteúdos, a linguagem e os métodos de base possuem as suas raízes na linguística e, particularmente, pela nossa opinião, nos estudos sobre variação linguística (diacronia, espacial, social, tipológica). Particularmente frutífera revelou-se a abordagem da tipologia linguística, que nos permitiu elaborar o interessante conceito de distância percebida: destacamos a função predominante da L1 que representa um ponto de referência crucial no processo da intercompreensão, da qual origina seja o efeito da distância seja a direção entre as línguas implicadas no processo. A consideração do diferente status das línguas envolvidas e a comparação das mesmas em uma ótica tipológica permite hipnotizar a oportunidade de distinguir, no âmbito da intercompreensão entre línguas românicas, diversos percursos de intercompreensão com base na L1 de partida. Esta distinção é suscetível de apresentar interessantes implicações no planejamento didático, delineando uma espécie de tipologia receptiva das línguas românicas que pode ser utilizada para criar percursos específicos de estudo das línguas estrangeiras.

Enfatizamos a possibilidade de conjugar na didática das línguas a "linguística das transparências" e a "linguística dos contrastes": as semelhanças e as diferenças constituem, de fato, dois aspectos complementares no ensino e aprendizagem das línguas que deveriam deslocar-se das afinidades às assimetrias, do objetivo de uma competência parcial e aproximativa ao desenvolvimento de uma competência mais global e formalmente mais cuidadosa e precisa.

A relação entre didática tradicional, centrada tradicionalmente em uma língua e levada a evidenciar contrastes entre L1 e L2, e didática simultânea de mais línguas, inspirada nos princípios da intercompreensão, levou-nos a explorar, de forma seletiva o trabalho de compreensão desenvolvido pelos aprendizes italianos envolvidos no experimento especificamente sobre uma das línguas românicas, o espanhol. A análise da atividade sobre o texto em espanhol evidenciou uma estrutura macrotextual de transparência evidente (identificável sobretudo nas áreas do léxico e da macrossintaxe), é uma área na qual as duas línguas se distanciam evidenciando alguns obstáculos à compreensão: conectivos textuais e particulares esquemas sintáticos. Um elemento importante à compreensão escrita são os traços peculiares do código escrito, como a ortografia e a pontuação. 


\section{DOSSIÊ ESPECIAL: DIDÁTICA SEM FRONTEIRAS \\ CHEREM, RAMMÉ, PEDRA \& OLMO (orgs.)}

Revista X, vol.2, 2014

Considerada a importância das implicações de política linguística ligadas ao conceito de intercompreensão, quisemos verificar o modo como é codificada essa noção no Quadro Comum de Referências, o qual constitui o ponto de indicação obrigatório quando se fala de educação linguística. Mesmo a intercompreensão podendo ser encarada como uma habilidade do tipo interativo, percebemos que na descrição da habilidade de interação não aparece o termo intercompreensão nem são contempladas as especificidades do processo interativo que existe na intercompreensão, sobretudo na intercompreensão escrita, que aparece como habilidade de fato mais explorada na prática didática. Para darmos conta disso sugerimos a possibilidade de introduzir: a) uma articulação na descrição da habilidade de interação com base na L1 envolvida (sendo uma única L1 ou diversas) e b) uma distinção entre intercompreensão escrita, oral e escrita e oral, com base na complexidade do canal de comunicação utilizado (somente escrito, somente oral, ou escrito e oral).

Concluindo, queremos enfatizar a forte valência da intercompreensão como instrumento de conhecimento e de aprofundamento da própria identidade social e comunitária assim como daquela individual e pessoal. Em um nível ainda mais abstrato, é possível conceber a intercompreensão como um comportamento de conhecimento.

Em uma comunidade europeia em continua expansão e evolução, caracterizada pelo crescente multilinguismo, a educação à intercompreensão entre línguas românicas representa um importante impulso de agregação e integração que pode contribuir de modo fundamental para a construção da consciência de fazer parte de uma única comunidade, com uma história cultural e linguística comum, promovendo assim, o nascimento de uma identidade românica e de um "orgulho românico" (Simone, 1997). Do ponto de vista da vida de cidadãos da Comunidade Europeia é fácil reconhecer que saber compreender textos escritos nas outras línguas românicas é uma competência que pode revelar-se muito útil e que contribui a incrementar o nível de liberdade de cada indivíduo, facilitando a comunicação, a circulação de ideias e de pessoas, o acesso aos conhecimentos, a mobilidade no trabalho, pois a incapacidade de "intercompreender-se" é um fator de fechamento, exclusão e discriminação.

O foco nas habilidades interculturais e interlinguísticas se reverbera na esfera do indivíduo incentivando a revisão e o aumento dos limites da própria identidade que não é feita somente de aspectos diferenciais mas também de elementos compartilhados, radicados em um passado comum e na proximidade geográfica. Em última análise, a 


\section{DOSSIÊ ESPECIAL: DIDÁTICA SEM FRONTEIRAS \\ CHEREM, RAMMÉ, PEDRA \& OLMO (orgs.)}

Revista X, vol.2, 2014

intercompreensão na sua essência mais profunda configura-se como comportamento conhecedor, uma forma de colocar-se diante daquilo que soma e ao lado do que divide. O percurso em direção à intercompreensão é um caminho que tem como finalidade o aprender a aprender, oferecendo-se assim como uma forma de metaconhecimento que pode ser colocado na base de uma "revolução" científica e cultural.

\section{REFERÊNCIAS BILBIOGRÁFICAS}

BALBONI, P.E. Dall'intercomprensione all'intercomunicazione romanza. In F. Capucho, P. Alves, A. Martins, C. Degache \& M. Tost (Eds.), Diálogos em Intercompreensão Lisbona: Universidade Católica Editora, 2007, pp. 447-459.

BENUCCI, A. Le lingue romanze: una guida all'intercomprensione. Torino: UTET Libreria, 2005.

BETTONI, C. Imparare un'altra lingua. Lezioni di linguistica applicata. RomaBari: Editori Laterza, 2001.

BLANCHE-BENVENISTE, C., VALLI, A., MOTA, M.A., SIMONE, R., BONVINO, E., UZCANGA DE VIVAR, I. EuRom4, metodo di insegnamento simultaneo delle lingue romanze. Firenze: La Nuova Italia. (con annesso CD- Rom), 1997.

BLANCHE-BENVENISTE, C. \& VALLI, A. Une grammaire pour lire en quatre langues. Le Français dans le monde, janvier, numéro spécial. Paris: Hachette, pp.33-37, 1997.

BONVINO, E. Intercomprensione. Percorsi di apprendimento/insegnamento simultaneo di portoghese, spagnolo, catalano, italiano e francese. In M. Mezzadri (Ed.), Le Lingue dell'educazione in un mondo senza frontiere. Perugia: Guerra Edizioni, 2010,pp. 211-222.

Intercomprensione: passato, presente, futuro. In E. Lombardi Vallauri \& L. Mereu (Eds.), Spazi linguistici. Studi in onore di Raffaele Simone. Roma: Bulzoni, 2009, pp. 229-243.

L'intercompréhension: une expérience italienne. Le Français dans le Monde, 340, Paris: Hachette, pp.26-28, 2005.

L'italiano e le sue sorelle. Didattica simultanea delle lingue romanze. Italiano \& Oltre, 3/2000, 116-119, 2000.

Il multilinguismo e l'intercomprensione. In: C. Serra Borneto (Ed.), C'era una volta il metodo. Roma: La Nuova Italia Scientifica, 1998,pp. 267-285.

BONVINO, E., CADDEO, S., DERANSARD, A., LE BESNERAIS, M. L'intercompréhension: un concept hétérogène, des enseignements ciblés. Le Français dans le Monde, n. 355. Paris: Hachette, pp.22-24, 2008.

BONVINO, E. \& CADDEO, S. L'intercompréhension à l'oral: où en est la recherche?. In F. Capucho, P. Alves, A. Martins, C. Degache \& M. Tost (Eds.), Diálogos em Intercompreensão. Lisbona: Universidade Católica Editora, 2007, pp. 523-533.

CAPUCHO, F., ALVES, P., MARTINS, A., DEGACHE, C., TOST, M. (Eds.) Diálogos em Intercompreensão. Lisbona: Universidade Católica Portuguesa, 2007.

CASTAGNE, E. L'avenir du patrimoine linguistique et culturel de l'Europe. In : Actes du Colloque International à Reims, 3 juillet 2003, 2004. 


\section{DOSSIÊ ESPECIAL: DIDÁTICA SEM FRONTEIRAS \\ CHEREM, RAMMÉ, PEDRA \& OLMO (orgs.)}

Revista X, vol.2, 2014

COMRIE, B. Universali del linguaggio e tipologia linguistica: sintassi e tipologia. Bologna: Il Mulino, 1983.

CONSEIL DE L'EUROPE/STRASBOURG. Cadre européen commun de référence pour les langues: apprendre, enseigner, évaluer. Paris: Les Éditions Didier. (Dernière consultation le 30/11/2010. Disponível em : www.coe.int/t/dg4/ linguistic/Source/Framework_FR.pdf.

DÉLÉGATION GÉNÉRALE À LA LANGUE FRANÇAISE ET AUX LANGUES DE FRANCE, Opuscolo Références sur EuRom5: une méthode d'intercompréhension. Paris (Dernière consultation le 30/11/2010, sur URL: http://www.dglf.culture.gouv.fr/publications/Eurom5 4.pdf), 2010.

Opuscolo Références sur l'intercompréhension entre langues apparentées. Paris (Dernière consultation le 30/11/2010, sur URL: http://www. culture.gouv.fr/culture/dglf/publications/intercomprehension.pdf), 2007.

DEPECKER, L. Entre signe et concept. Eléments de terminologie générale. Paris: Presses Sorbonne Nouvelle, 2002.

FAONE, S. Il progetto EuRom5 - l'intercomprensione tra lingue romanze - una sperimentazione a Roma Tre. Tesi Triennale, Università degli Studi Roma Tre, 2009. JACKOBSON, R. Essais de linguistique générale. Paris: Éditions de Minuit, 1963. JAMET, M.C. L'intercompréhension: de la définition d'un concept à la délimitation d'un champ de recherche ou vice versa?. Autour de la définition. Publifarum, n. 11. (Dernière consultation le 18/11/2010, sur URL: http:// publifarum.farum.it/ezine_articles.php?id=144), 2010.

. Orale e intercomprensione tra le lingue romanze. Ricerche e implicazioni didattiche. Venezia: Le Bricole, Editrice Cafoscarina srl, 2009.

Le strategie cognitive nel processo di intercomprensione. Scritto e orale a confronto. In A. Benucci (Ed.), Le lingue romanze: una guida all'intercomprensione Torino: UTET Libreria, 2005, pp. 15-54.

PALLOTTI, G. La seconda lingua. Milano: Strumenti Bompiani, 1998.

SCIPIONI, C. Lettura e lingua straniera. Perugia: La Nuova Italia, 1990.

SELINKER, L. Rediscovering interlanguage. London: Longman, 1992.

SERRA BORNETO, C. C'era una volta il metodo: tendenze attuali della didattica delle lingue straniere. Roma: Carocci, 1998.

SIMONE, R. Langues romanes de toute l'Europe, unissez-vous!. Le français dans le monde, janvier, numéro spécial. Paris: Hachette, 1997, pp. 25-32.

SCHMITT JENSEN, J. L'expérience danoise et les langues romanes. Le français dans le monde, Janvier, numéro spécial. Paris: Hachette, 1997, pp. 95-108,

TOST PLANET, M. I progetti europei d'intercomprensione tra parlanti di lingue romanze. In A. Benucci (Ed.), Le lingue romanze: una guida all'intercomprensione Torino: UTET Libreria, 2005, pp. 15-54. 